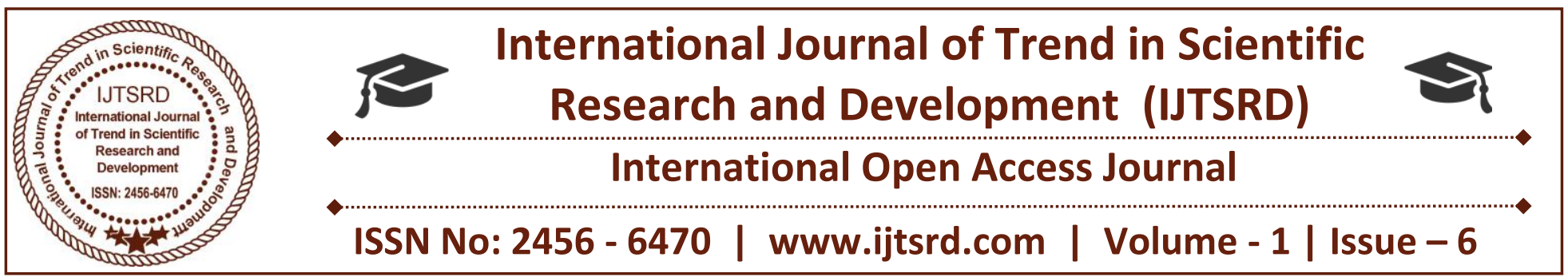

\title{
A Shift in Emphasis in Performance Appraisals
}

\author{
Somnath Sanka \\ Research Scholar, Department of Management, \\ Research Studies, Rayalaseema University, Kurnool, Andhra Pradesh
}

Much literature has pointed to the problems with performance appraisals, which has led some commentators to call for abolition of the process or a renewed focus on the core elements of performance appraisal. For example, Coens and Jenkins based on their experience in North America recommended 'abolishing performance appraisals' (2000) 1, citing regular failings in development planning, objective setting and 360 degree feedback. They advocate instead broader performance management approaches focused on customer outcomes and decoupling the complex mix of processes often tied up inside performance appraisal. They cite a Police Department in Madison, Wisconsin which replaced traditional appraisals with a system of individual goal setting, leadership training and employee involvement that let officers choose who they wanted to work with and who supervised them. A US Department of Justice comparative study found that Madison had the highest levels of citizen satisfaction following the changes.

Gratton and Ghoshal (2002) 2 argue that at all levels, the emphasis should be on the core of the appraisal and development process, that is 'improving the quality of conversations', rather than going through 'dehydrated rituals', with open and honest leaders setting the example for a culture of curious, creative learning organisations. Cunneen (2006) 3 also highlight the issue of managers and employees simply going through the motions of the process when he stated:

'Not only do managers dislike carrying out performance appraisals but many admit that it is the most dreaded task in their calendar. Too often it leads to a shallow discussion, with both parties colluding to meet the organisation's prescribed administrative procedure and, in doing so, avoiding the more fundamental issue of performance improvement.'

These failings of appraisal have led to new approaches to performance management.

Hurst (2009) 4 discerns two strands in the performance management literature: a very structured and controlled backward-looking review approach which is 'done' to employees (Grote, 2000) 5, and a much more inclusive, forward-looking approach involving the individual, supporting their development and linking in to the organisation's needs and values (Spangenburg and Theron, 2001) 6 . But as Cannell (2006) 7 points out, there is still the need for a conversation to both reflect on past performance and to look forward.

The latter is what is largely in the mind of those that advocate a more root and branch change to performance appraisal: a switch to a performance management philosophy that engages employees more in the process and drives performance towards key organisation goals. The concurrent simplification of processes that is underway switches the focus on individual scheme details and towards the essence of the performance management process.

In their book on the subject, Armstrong and Baron (2005) 8 note the shift in terminology from performance appraisal to performance management, 
which they believe indicates a wider shift in the philosophy and content of the process:

'Performance appraisal has a reputation as a punitive, top-down control device, an unloved system. Performance Management is a holistic, total approach to engaging everyone in the organisation in a continuous process, to improve everyone and their performance, and thereby the performance of the whole organisation.'

Despite the move to adopt an all-encompassing approach, a recent trend towards simplification is also evident from CIPD research, with better support and training being provided as greater focus is being put on how these systems actually work in the reality of the organisation, rather than in respect of the many intended policy intention and outcomes.

Just under half of the respondents to the CIPD performance management survey (48 per cent) had proposed to make changes to their performance management arrangements over the forthcoming year, with a similar direction evident (CIPD, 2005).

E-reward's survey (2005) 9of performance management provides a clear picture of the changes that organisations are making to support the shift towards a performance management approach, but also to address problems such as over complexity and bureaucracy. More than two-thirds of organisations in the Ereward research had either changed their systems in the past three years or were planning to make changes in the future.

Colville \& Millner (2011) 10 recognise that 'a trap that organisations can fall into is not recognising that the implementation of performance management is a change process. Too often, organisations just look over the fence to what others are doing and do the same'. They argue that this practice is reasonable but it needs to be coupled with an understanding of how the process will 'deliver organisation strategy and vision'. In order to achieve this, they argue HR needs to have an awareness of the 'current state', the 'desired state' of the organisation and its processes.

\section{REFERENCES}

1) Coens $T$, Jenkins $M$ (2000), Abolishing Performance Appraisals and What to do Instead, Berrett-Koehler

2) Gratton L, Ghoshal S (2002), 'Improving the Quality of Conversations', Organisation Dynamics

3) Cunneen P, (2006), 'How to...improve performance management', People Management, 12 January, pp. 42-43

4) Hurst J (2009), An evaluation of the effectiveness of the national KSF system for NHS staff, Doctorate of Education thesis (unpublished)

5) Grote D (2000), 'Public Sector Organisations', Public Personnel Management, Vol. 29 (1), pp. 121

6) Spangenburg H, Theron $\mathrm{C}$ (2001), 'Adapting the Systems Model of Performance Management', South African Journal of Business Management, Vol. 32 (1), pp. 35-48

7) Cannell M (2006), Performance management: an overview, CIPD website

8) Armstrong M, Baron A (2004), 'Get into Line', People Management,

9) E-reward (2005), What is Happening in Performance Management Today: Part 1 - Survey Findings, Research report No. 32, E-reward

10) Colville K, Millner D (2011), 'Embedding performance management: understanding the enablers for change', Strategic HR Review, Vol. 10, No. 1 